\title{
Transanal Total Mesorectal Excision: Is There a Real Advantage? The Baltic View
}

\author{
Saulius Mikalauskas ${ }^{\mathrm{a}, \mathrm{b}}$ Simonas Uselis ${ }^{\mathrm{a}}$ Digne Jurkeviciute ${ }^{\mathrm{b}}$ Tomas Poskus ${ }^{\mathrm{a}, \mathrm{b}}$ \\ Eligijus Poskus ${ }^{a, b}$ Kestutis Strupas ${ }^{a, b}$ \\ ${ }^{a}$ Center of Abdominal Surgery, Vilnius University, and ${ }^{\mathrm{b}}$ Faculty of Medicine, Vilnius University, Vilnius, Lithuania
}

\section{Keywords}

Minimally invasive $\cdot$ Rectal cancer $\cdot$ Surgery $\cdot$ taTME $\cdot$ Total mesorectal excision

\section{Abstract}

Background: The novel surgical procedure transanal total mesorectal excision (taTME) has rapidly become an interest of research in order to overcome the shortcomings of laparoscopic surgery in the treatment of middle and low rectal cancer. taTME is a new natural orifice transluminal endoscopic surgery modality combining three rectal surgery techniques. Methods: A retrospective clinical study was conducted in a single centre for a period of 3 years, and herein we report on our first 25 taTME procedures in patients with middle and lower third rectal adenocarcinoma. Results: The main demographics were evaluated. The mean age of patients was $64 \pm 12$ years. There were predominantly males (72\%) and 7 female patients (28\%) with an average body mass index of $29 \pm 4.8 \mathrm{~kg} / \mathrm{m}^{2}$. High blood pressure, obesity, chronic heart insufficiency, chronic atrial fibrillation, and diabetes mellitus were commonly diagnosed in all patients. A circumferential resection margin $>1 \mathrm{~mm}$ was achieved in $16 \%(n=4),>2 \mathrm{~mm}$ in $40 \%(\mathrm{n}=10)$, and $>3 \mathrm{~mm}$ in $44 \%(\mathrm{n}=$ 11) of operated patients. The average CRM was $1.8 \pm 0.9 \mathrm{~cm}$. In $24 \%$ of cases, the distance of a tumour from the mesorectal fascia (MRF) was $<1 \mathrm{~mm}$; meanwhile, for $76 \%$ of patients, the tumour margin was $>1 \mathrm{~mm}$ from the MRF. Recovery to flatus was $3 \pm 1$ days. The average length of hospital stay was $11 \pm 3$ days. The overall postoperative morbidity was $8 \%$, i.e. one (4\%) complication classified as Clavien-Dindo degree I and one (4\%) major (IIlb) complication. Subsequently, all patients successfully recovered and were discharged from hospital. During the follow-up period no cancer recurrence was observed. Conclusion: Our results nicely demonstrate that taTME can be safely performed with acceptable perioperative complications in patients with middle or lower third rectal cancer. In addition, the perioperative morbidity is also acceptable. However, taTME remains a technically highly demanding operation but is feasible and safe after the appropriate experience is gained. Nevertheless, larger multicentre prospective randomised studies are ongoing to confirm the safety and to verify oncological results when compared to laparoscopic rectal surgery.

(c) 2019 S. Karger AG, Basel

\section{Introduction}

The knowledge and treatment of rectal cancer has improved over the last 30 years. Total mesorectal excision (TME) has become crucial in rectal surgery, as proposed by Heald $[1,2]$. Firstly, TME was introduced in open surgery, and the development of minimally invasive surgery led to the era of laparoscopic TME (laTME) and research in this field. Thus, it has been proven that laparoscopic

S.M. and S.U. contributed equally to this work.

Data from this manuscript have in part been presented at the 9th Congress of the Baltic Association of Surgeons (Klaipeda, Lithuania; May 10-12, 2018).

\section{KARGER}

(c) 2019 S. Karger AG, Basel
Assoc. Prof. Saulius Mikalauskas, MD, $\mathrm{PhD}$

Faculty of Medicine, Vilnius University Hospital "Santaros Klinikos" Santariskiu St. 2

LT-08611 Vilnius (Lithuania)

E-Mail saulius.mikalauskas@santa.lt 
rectal cancer surgery is safe from the oncological perspective and allows a faster recovery after surgery [3]. Compared to open surgery, laTME has been associated with lesser pain, earlier return to work, and shorter hospital stays [4-6]. It has been postulated that these advantages are due to decreased inflammatory processes after laparoscopic surgery $[7,8]$. However, the laparoscopic approach for middle and lower rectum cancer is still a challenge even for experienced surgeons, especially in obese male patients [9]. Furthermore, Bondeven et al. [10] demonstrated that residual mesorectum is present in $36 \%$ of patients who underwent open as well as laparoscopic surgery. Thus, a new kind of minimally invasive surgical procedure, i.e. transanal TME (taTME), has rapidly become of interest in minimally invasive surgery research [1114]. Besides conventional laparoscopic surgery, taTME has been introduced in order to ease the technical aspects of mesorectal excision from the bottom towards the pelvis. taTME was first reported by Sylla et al. [15] in 2010. It is a new minimally invasive technique for rectal cancer surgery where the most distal and complicated part of TME surgery is performed transanally using endoscopic instruments. It starts at the distal part of the TME plane and thus it results in a complete TME specimen and improves the quality of excision of mesorectum [15].

Herein, we present a case series of 25 patients who had histologically confirmed middle or lower rectum adenocarcinoma and underwent taTME operations.

\section{Patients and Methods}

A retrospective clinical study was performed at the Vilnius University Hospital 'Santaros Klinikos', Lithuania. In the last 3-year period, all of our first 25 patients, who were diagnosed with middle or lower third rectum cancer and who were determined for surgical treatment after multidisciplinary consideration, were included in this study. All of them underwent a taTME, thus being the first 25 cases of taTME at our institution. The following variables were collected and studied: age, sex, cancer location from anal verge and stage, body mass index (BMI), comorbidities, American Society of Anaesthesiologists (ASA) scores distribution, the operation performed, operative time, length of resected specimen, count of lymph nodes harvested, circumferential resection margin (CRM), intraoperative complications, blood loss, recover to flatus, length of hospital stay, and postoperative complications within 30 days. The severity of complications was assessed by the Clavien-Dindo classification.

Descriptive statistics for qualitative data are presented in frequency tables, and for quantitative data, mean values with standard deviations are presented. Gathered data was analysed using IBM SPSS Statistics 21 statistical analysis software.

Surgical Technique

Under general anaesthesia the patient is placed in the lithotomy position. A taTME operation is performed concomitantly by two teams. In all cases the transanal part of the operation was performed by the same surgeon.
Table 1. Baseline characteristics of the patients and surgery

\begin{tabular}{lc}
\hline Characteristics & Mean \pm SD (range) \\
\hline Age, years & $64.0 \pm 12.3(39-83)$ \\
BMI, kg/m ${ }^{2}$ & $29.0 \pm 4.8(22.2-41.3)$ \\
Location of tumor, cm from AV & $7.8 \pm 2.3(2-12)$ \\
Operative time, min & $282 \pm 76(175-505)$ \\
Blood loss, ml & $160 \pm 114(0-400)$ \\
Length of specimen, cm & $19.5 \pm 12.7(10-67)$ \\
Harvested LN & $19 \pm 8(10-40)$ \\
CRM, cm & $1.8 \pm 0.9(0.1-4)$ \\
Recover to flatus, days & $3 \pm 1(2-6)$ \\
LOS, days & $11 \pm 3(7-18)$ \\
\hline
\end{tabular}

BMI, body mass index; AV, anal verge; OT, operative time; LN, lymph nodes; CRM, circumferential margin; LOS, length of hospital stay; SD, standard deviation.

The abdominal and perineal operative fields are prepared for transabdominal and transanal access. Firstly, a small longitudinal incision is made above the umbilicus, and the pneumoperitoneum of $12 \mathrm{~mm} \mathrm{Hg}$ is established using a Veress needle. A $10-\mathrm{mm}$ trocar is inserted and the abdominal cavity is explored to evaluate if the disease has not spread and if the case is suitable for the laparoscopic-assisted taTME procedure. After confirmation, one 12-mm trocar is inserted in the right iliac fossa region and two other $10-\mathrm{mm}$ trocars in the right and left paraumbilical regions. The descending and sigmoid colon are mobilized from the lateral side while the left ureter is identified. In some patients, full mobilization of the splenic flexure is carried out. The high ligation of the inferior mesenteric vein and artery is performed intracorporeally. At the same time, the anus is dilated and the transanal port is inserted by the perineal team. A SILS ${ }^{\mathrm{TM}}$ Port (Covidien, Medtronic, Dublin, Ireland) with a $12-\mathrm{mm}$ port for camera and two $5-\mathrm{mm}$ working ports was used for the first two cases, a TriPort ${ }^{\circledR}$ (Olympus, Europe Holding GmbH, Hamburg, Germany) for the third case, a GelPOINT (Applied Medical, Rancho Santa Margarita, CA, USA) for the fourth case, and the rest of the cases were treated by using Storz TEO $^{\circledR}$ B-Port (Karl Storz GmbH, Tuttlingen Germany). The pneumorectum $(10-15 \mathrm{~mm} \mathrm{Hg}$ ) is established and a purse-string PDS 2/0 suture is placed below the tumour under direct vision and tied securely. Then, the distal mucosa is initially marked circularly using a diathermy hook. After that, the dissection is performed using a diathermy hook (inferiorly to superiorly). Posterior dissection is performed in front of the presacral fascia to preserve the mesorectal envelope. Anterior dissection is started when entering the rectovaginal septum in females and the rectoprostatic plane for males. Lateral dissection connects the anterior and posterior planes bilaterally until the peritoneum is completely opened. Transversal 5-cm minilaparotomy above the pubic symphysis is performed and the bowel is extraperitonised. Bowel resection is performed extracorporeally and the anvil of the stapler is inserted into the proximal colon. The purse-string suture is placed on the anvil for end-to-end stapler anastomosis and the bowel is reinserted into the abdominal cavity. A second pursestring suture is placed in the distal rectum stump through the transanal device and tied, thus fully closing it. The shaft of a 29mm AutoSuture CEEA ${ }^{\circledR}$ circular stapler (Covidien, Medtronic, Dublin, Ireland) is inserted through the anus and the end-to-end stapler anastomosis is formed under laparoscopic visualisation. An intraoperative anastomotic air leak test is performed and the 
Table 2. American Society of Anesthesiologists (ASA) score distribution between patients

\begin{tabular}{lc}
\hline ASA classification & Total $(\mathrm{n}=25)$ \\
\hline I & $4(16 \%)$ \\
II & $11(44 \%)$ \\
III & $9(36 \%)$ \\
IV & $1(4 \%)$ \\
\hline
\end{tabular}

Table 3. Frequency of the comorbidity

\begin{tabular}{lrr}
\hline Comorbidity & Total $(\mathrm{n}=25)$ & Frequency, \% \\
\hline BA & 2 & 8 \\
HBP & 11 & 44 \\
CAF & 5 & 20 \\
COPD & 4 & 16 \\
BPH & 3 & 12 \\
Obesity & 8 & 32 \\
IC & 5 & 20 \\
Depression & 1 & 4 \\
DM & 4 & 16 \\
CH & 1 & 4 \\
CRF & 1 & 4 \\
PC & 1 & 4 \\
Hemiparesis & 1 & 4 \\
None & 4 & 16
\end{tabular}

$\mathrm{BA}$, bronchial asthma; HBP, high blood pressure; $\mathrm{CAF}$, chronic atrial fibrillation; COPD, chronic obstructive pulmonary disease; $\mathrm{BPH}$, benign prostatic hyperplasia; IC, heart insuffiency; DM, diabetus mellitus; $\mathrm{CH}$, hepatic cirrhosis; $\mathrm{CRF}$, chronic renal failure; PC, chronic pancreatitis.

drain is left intra-abdominally. Preventive ileostomy is formed in the right paraumbilical port place. The diverting ileostomy was closed 6-8 weeks after primary surgery if a sigmoidoscopy and computed tomography scan with contrast enema did not show any evidence of anastomotic failure.

\section{Results}

A total of 25 taTMEs due to middle and lower third rectum cancer have been performed. The main baseline characteristics of the patients and surgery are shown in table 1. Briefly, the mean age of patients was $64.0 \pm 12.3$ years (range $39-83$ years). There were predominantly male (18 males (72\%) and 7 females (28\%)). The average BMI of patients was $29.0 \pm 4.8 \mathrm{~kg} / \mathrm{m}^{2}$ (range $22.2-41.3 \mathrm{~kg} /$ $\left.\mathrm{m}^{2}\right)$. There were $4(16 \%), 11(44 \%), 9(36 \%)$, and $1(4 \%)$ patients with ASA score of I, II, III, and IV, respectively (table 2). High blood pressure, obesity, chronic heart insufficiency, chronic atrial fibrillation, and diabetes mellitus were commonly diagnosed in $44,32,20,20$, and $16 \%$ of all patients, respectively (table 3 ).
Table 4. Distribution of the patients according to circumferential resection margin (CRM) value

\begin{tabular}{lc}
\hline CRM, mm & $\begin{array}{l}\text { Number of patients }(\mathrm{n}=25) \\
\text { (frequency, \%) }\end{array}$ \\
\hline$>1$ & $4(16 \%)$ \\
$>2$ & $10(40 \%)$ \\
$>3$ & $11(44 \%)$ \\
\hline
\end{tabular}

Table 5. State of mesorectal fascia (MRF) according to the Mercury classification

\begin{tabular}{lc}
$\begin{array}{l}\text { Shortest distance between tumour } \\
\text { to MRF }\end{array}$ & $\begin{array}{l}\text { Number of patients } \\
(\mathrm{n}=25) \text { (frequency, \%) }\end{array}$ \\
\hline $\begin{array}{l}\text { MRF involved, distance } \leq 1 \mathrm{~mm} \\
\text { MRF not involved, distance }>1 \mathrm{~mm}\end{array}$ & $\begin{array}{r}6(24 \%) \\
19(76 \%)\end{array}$
\end{tabular}

Distance between tumour to the MRF is the most powerful predictor for local recurrence. $1-2 \mathrm{~mm}=$ the MRF is threatened, $>2$ $\mathrm{mm}=$ the $\mathrm{MRF}$ is safe.

Table 6. UICC TNM classification of malignant tumours (ed 8th)

\begin{tabular}{lll}
\hline Stage & Stage characteristics & $\begin{array}{c}\text { Total, }(\mathrm{n}=25) \\
\text { (frequency, \%) }\end{array}$ \\
\hline 0 & Tis N0 M0 & $2(8)$ \\
I & T1,T2 N0 M0 & $6(24)$ \\
IIA & T3 N0 M0 & $10(40)$ \\
IIB & T4a N0 M0 & 0 \\
IIC & T4b N0 M0 & 0 \\
IIIA & T1, T2 N1 M0 & $3(12)$ \\
& T1 N2a M0 & $2(8)$ \\
IIIB & T1, T2 N2b M0 & \\
& T2, T3 N2a M0 & \\
IIIC & T3, T4a N1 M0 & $1(4)$ \\
& T3, T4a N2b M0 & \\
TVA & T4b N1, N2 M0 & $1(4)$ \\
IVB & any T Any N M1a & 0 \\
IVC & any T Any N M1b & 0 \\
\hline
\end{tabular}

The average operative time was $282 \pm 76$ min (range $175-505 \mathrm{~min}$ ) with an average blood loss of $160 \pm 114 \mathrm{ml}$ (range $0-400 \mathrm{ml}$ ). The tumour distance from the anal verge was $7.8 \pm 2.3 \mathrm{~cm}$ (range $2-12 \mathrm{~cm}$ ), and the average length of resected specimen was $19.5 \pm 12.7 \mathrm{~cm}$ (range 10-67 cm). The count of harvested lymph nodes was 19 \pm 8 (range 10-40). A CRM of more than $1 \mathrm{~mm}$ was achieved in $16 \%(\mathrm{n}=4)$, more than $2 \mathrm{~mm}$ in $40 \%(\mathrm{n}=10)$, and more than $3 \mathrm{~mm}$ in $44 \%(\mathrm{n}=11)$ of operated patients (table 4 ). An average CRM was $1.8 \pm 0.9 \mathrm{~cm}$ (range $0.1-4$ $\mathrm{cm}$ ). The quality of TME was evaluated by the distance of the tumour from the mesorectal fascia (MRF) as it is one 
Table 7. Classification of surgical complications (the Clavien-Dindo system)

\begin{tabular}{lcc}
\hline Grades & Total $(\mathrm{n}=25)$ & Frequency, \% \\
\hline I & 23 & 92 \\
I & 1 & 4 \\
II & 0 & 0 \\
III & & \\
$\quad$ a & 0 & 0 \\
$\quad$ b & 1 & 4 \\
IV & 0 & 0 \\
$\quad$ a & 0 & 0 \\
b & 0 & 0 \\
V & & \\
\hline
\end{tabular}

of the predictors of local recurrence. In $24 \%$ of cases, the distance of the tumour from the MRF was less than $1 \mathrm{~mm}$, while for $76 \%$ of patients, the tumour margin was more than $1 \mathrm{~mm}$ from the MRF (table 5). Complete MRF evaluation according to the Mercury classification has not been established at our institution yet. Recovery to flatus occurred in $3 \pm 1$ (2-6) days. The average length of hospital stay was $11 \pm 3$ days (range 7-18 days). Regarding TNM classification, there was a total of $6(24 \%), 10(40 \%)$, $6(24 \%)$, and 1 (4\%) cases of stage I, II, III, and IV disease, respectively. In $2(8 \%)$ patients, a tumour in situ was diagnosed (table 6). Neoadjuvant chemotherapy was given to 12 patients (48\%). A diverting ileostomy was performed in all operated patients.

The overall postoperative morbidity was $8 \%$; there was one (4\%) complication being classified as Clavien-Dindo degree I. Nevertheless, there was one (4\%) major (IIIb) complication (table 7). A patient who had been clinically diagnosed with postoperative peritonitis underwent a laparotomy, and during the operation a perforation of the small intestine was identified. The defect was sutured, and the cavity of the abdomen was washed out and drained. The patient was discharged 2 weeks later.

Other minor complications, such as postoperative ileus of the small intestine, were managed conservatively. Subsequently, all patients successfully recovered and were discharged from hospital.

During long-term follow-up, a stricture of the anastomotic site was diagnosed in 2 patients and treated with endoscopic dilatation during sigmoidoscopy. In one case, due to vesicocolic fistula, the patient was reoperated, and the defect was sutured. In another case, an anastomotic site sinus was diagnosed and managed conservatively; no additional interventions were needed. After ultra-low anastomosis, a clinically non-relevant small anastomotic defect was diagnosed in 1 patient during sigmoidoscopy; nevertheless, deileostomy was performed, and the postoperative period was uneventful. During the follow-up period no cancer recurrence was observed.

\section{Discussion}

Nowadays, TME is a gold standard for locally advanced middle and lower third rectum tumours. Firstly, TME was introduced in open surgery as the standard of care for patients with rectal cancer. During the last two decades, however, laparoscopic surgery has emerged as an equal alternative for colorectal cancer. In addition, the COLOR II trial confirmed the safety of the laparoscopic approach. Moreover, the positive CRM remains high $(10 \%)$ in both open and laparoscopic TME groups ( $\mathrm{p}=$ 0.850 ) but suggests a significantly lower risk of positive CRM in laparoscopic cases among the subgroup of low rectal cancer patients $(\mathrm{p}=0.014)$ [16].

It was suggested that the greater the CRM, the better the prognosis in R0 patients. In these studies, compared to a CRM $>2 \mathrm{~mm}$ or $>1 \mathrm{~mm}$, a CRM $>3 \mathrm{~mm}$ was associated with lower local recurrence and better disease-free survival $[17,18]$.

Recently, Similis et al. [19] presented a systematic review of 510 taTME cases and showed a 5\% CRM involvement and $0.3 \%$ distal resection margin (DRM) positivity. Moreover, the most current systematic review and metaanalysis of 859 patients showed a better CRM and a lower positive CRM rate in the taTME versus the laTME group [20]. In our case series, the average CRM was $1.8 \pm 0.9 \mathrm{~cm}$; in addition, a CRM $>3 \mathrm{~mm}$ was achieved in $44 \%$ of cases, and this is within a satisfactory range compared to the data of the other authors mentioned above.

Veltcamp Helbach et al. [21] introduced 80 patients with 2.5\% CRM and 0\% DRM involvement after taTME. Lacy et al. [22] reported results of 140 patients who underwent taTME. The 9 patients (6.4\%) with an involved CRM were correctly diagnosed preoperatively with magnetic resonance imaging and had a complete mesorectal specimen after the operation. Burke et al. [23] showed a $4 \%$ CRM and a $2 \%$ DRM positivity in a study encompassing 50 patients.

Complete mesorectal excision is another important prognostic factor for middle and low third rectum cancer [24]. taTME surgery is an innovative surgical technique where the rectum is dissected transanally using TME principles; the procedure is called 'down-to-up' technique. Residual mesorectal tissue was detected in $3.1 \%$ of taTME patients and in $46.9 \%$ of laTME patients ( $\mathrm{p}<$ 0.001 ). The type of surgery was identified as a risk factor for leaving residual mesorectum. Other known risk factors for incomplete TME, such as BMI and male gender, were not significant [25].

Bondeven et al. [10] reported residual mesorectum in $36 \%$ of patients who, based on the size of the tumour, should have had a TME. However, the majority of these patients underwent open TME. 
In addition, open or laparoscopic TMEs show a similar macroscopically incomplete specimen rate and account for $3 \%$ in both groups [16].

Moreover, one meta-analysis showed that the mesenchymal complete resection rate in the taTME group was 1.9 times higher than that in the laTME group; a better CRM and a lower rate of positive CRMs were identified in the taTME group compared to the laTME group [20]. These results are promising.

TME is a cornerstone of rectal surgery in all types of surgical approaches [2]. taTME surgery is a novel surgical technique that adapts the concept of natural orifice transluminal endoscopic surgery (NOTES), which allows to start the dissection of mesorectum from the bottom, the most distal part of mesorectum plane, i.e. the most challenging part of the TME. Nevertheless, due to its complexity, the usage of different minimally invasive techniques in taTME is associated with a significant rate of intraoperative rectal, vaginal, or bladder injury during the learning curve, mainly due to the anatomical landmarks which are different from those during standard laTME from above. However, beyond the learning curve, the rate of intraoperative complications decreases [26-28]. Postoperative outcomes and oncological results of taTME and laTME were reported by several retrospective and comparative studies to be similar. Nevertheless, others have also reported specific intraoperative complications observed during taTME, such as urethral or bladder injury and rectal or vaginal perforation [11-14, 29-31]. Despite that, in our first 25 cases with middle or lower third rectum cancer, we managed to avoid severe operative complications most likely due to previous training and very thorough preparation. In addition, the postoperative morbidity of $8 \%$ is also within accepted limits.

Another important obstacle in rectal surgery is anastomotic leakage which is usually solved by systematic diverting ileostomy. Although higher leak rates have been attributed to low surgical volume [32, 33], Hyman et al. [34] found that even in a group of high-volume surgeons the leak rates still ranged from 1.6 to $9.9 \%$, despite more surgical experience and high case load. Recently, Penna et al. [35] reported on the overall anastomotic failure rate of $15.7 \%$ after taTME. This included early $(7.8 \%)$ and delayed leak (2.0\%), pelvic abscess (4.7\%), anastomotic fistula $(0.8 \%)$, chronic sinus $(0.9 \%)$, and anastomotic stricture (3.6\%). Independent risk factors of anastomotic failure were: male sex, obesity, smoking, diabetes mellitus, tumours $>25 \mathrm{~mm}$, excessive intraoperative blood loss, manual anastomosis, and prolonged perineal operative time. In our experience, we had only 2 patients with asymptomatic anastomotic leakage before performing deileostomy. Further analysis of risk factors of anastomotic leakage is needed regarding the frequency of anastomosis.

\section{Conclusions}

In recent years, taTME has been rapidly evolving in the treatment for middle and lower third rectum cancer. Accumulating evidence indicates that taTME is safe and even offers better oncological results compared with laTME or open surgery. However, these data should be taken into consideration with caution because of the retrospective nature of the present study and due to the selection of cases. Nevertheless, taTME remains a technically highly demanding operation but is feasible and safe after appropriate experience has been gained. In addition, larger multicenter prospective randomised studies are ongoing to confirm the safety and better oncological results compared to laparoscopic rectal surgery.

\section{Disclosure Statement}

The authors do not have any competing interests to declare regarding this article.

\section{References}

$>1$ Heald RJ: A new approach to rectal cancer. Br J Hosp Med 1979;22:277-281.

12 Heald RJ, Husband EM, Ryall RDH: The mesorectum in rectal cancer surgery - the clue to pelvic recurrence? Br J Surg 1982;69:613-616.

>3 Bonjer HJ, Deijen CL, Abis GA, Cuesta MA, van der Pas MHGM, de Lange-de Klerk ESM, Lacy AM, Bemelman WA, Andersson J, Angenete E, Rosenberg J, Fuerst A, Haglind E: A randomized trial of laparoscopic versus open surgery for rectal cancer. N Engl J Med 2015; 372:1324-1332.

4 Guillou PJ, Quirke P, Thorpe H, Walker J, Jayne DG, Smith AM, Heath RM, Brown JM; MRC CLASICC trial group: Short-term endpoints of conventional versus laparoscopicassisted surgery in patients with colorectal cancer (MRC CLASICC trial): multicentre, randomised controlled trial. Lancet 2005;365: $1718-1726$.

5 Leung KL, Kwok SP, Lam SC, Lee JF, Yiu RY, Ng SS, Lai PB, Lau WY: Laparoscopic resection of rectosigmoid carcinoma: prospective randomised trial. Lancet 2004;363:11871192.

6 Veldkamp R, Kuhry E, Hop WC, Jeekel J, Kazemier G, Bonjer HJ, Haglind E, Påhlman L, Cuesta MA, Msika S, Morino M, Lacy AM; COlon cancer Laparoscopic or Open Resection Study Group (COLOR): Laparoscopic surgery versus open surgery for colon cancer: short-term outcomes of a randomised trial. Lancet Oncol 2005;6:477-484.

7 Delgado S, Lacy AM, Filella X, Castells A, García-Valdecasas JC, Pique JM, Momblán D, Visa $\mathrm{J}$ : Acute phase response in laparoscopic and open colectomy in colon cancer: randomized study. Dis Colon Rectum 2001;44:638-646.

$>8$ Harmon GD, Senagore AJ, Kilbride MJ, Warzynski MJ: Interleukin-6 response to laparoscopic and open colectomy. Dis Colon Rectum 1994;37:754-759.

-9 Targarona EM, Balague C, Pernas JC, Martinez C, Berindoague R, Gich I, Trias M: Can we predict immediate outcome after laparoscopic rectal surgery? Multivariate analysis of clinical, anatomic, and pathologic features after 3-dimensional reconstruction of the pelvic anatomy. Ann Surg 2008;247:642-649.

10 Bondeven P, Hagemann-Madsen RH, Laurberg S, Ginnerup Pedersen B: Extent and completeness of mesorectal excision evaluated by postoperative magnetic resonance imaging. Br J Surg 2013;100:1357-1367. 
11 Velthuis S, Nieuwenhuis DH, Ruijter TEG, et al: Transanal versus traditional laparoscopic total mesorectal excision for rectal carcinoma. Surg Endosc 2014;28:3494-3499.

$>12$ Fernandez-Hevia M, Delgado S, Castells A, et al: Transanal total mesorectal excision in rectal cancer. Ann Surg 2015;261:221-227.

$\checkmark 13$ Perdawood SK, Al Khefagie GAA: Transanal vs laparoscopic total mesorectal excision for rectal cancer: initial experience from Denmark. Colorectal Dis 2016;18:51-58.

14 Chouillard E, Regnier A, Vitte R-L, et al: Transanal NOTES total mesorectal excision (TME) in patients with rectal cancer: is anatomy better preserved? Tech Coloproctol 2016;20:537-544.

$\checkmark 15$ Sylla P, Rattner DW, Delgado S, Lacy AM: NOTES transanal rectal cancer resection using transanal endoscopic microsurgery and laparoscopic assistance. Surg Endosc 2010;24: 1205-1210.

$>16$ van der Pas MH, Haglind E, Cuesta MA, Fürst A, Lacy AM, Hop WC, Bonjer HJ; COlorectal cancer Laparoscopic or Open Resection II (COLOR II) Study Group: Laparoscopic versus open surgery for rectal cancer (COLOR II): short-term outcomes of a randomised, phase 3 trial. Lancet Oncol 2013;14:210-218.

-17 Nagtegaal ID, Marijnen CA, Kranenbarg EK, et al: Circumferential margin involvement is still an important predictor of local recurrence in rectal carcinoma: not one millimeter but two millimeters is the limit. Am J Surg Pathol 2002;26:350-357.

18 Bernstein TE, Endreseth BH, Romundstad P, Wibe A; Norwegian Colorectal Cancer Group: Circumferential resection margin as a prognostic factor in rectal cancer. Br J Surg 2009;96:1348-1357.

19 Simillis C, Hompes R, Penna M, Rasheed S, Tekkis PP: A systematic review of transanal total mesorectal excision: is this the future of rectal cancer surgery? Colorectal Dis 2016;18: 19-36.
20 Hu D, Jin P, Hu L, Liu W, Zhang W, Guo T, Yang X: The application of transanal total mesorectal excision for patients with middle and low rectal cancer. A systematic review and meta-analysis. Medicine 2018;97:e11410. 21 Veltcamp Helbach M, Deijen CL, Velthuis S,
Bonjer HJ, Tuynman JB, Sietses C: Transanal total mesorectal excision for rectal carcinoma: short-term outcomes and experience after 80 cases. Surg Endosc 2016;30:464-470.

22 Lacy AM, Tasende MM, Delgado S, Fernandez-Hevia M, Jimenez M, De Lacy B, Castells A, Bravo R, Wexner SD, Heald RJ: Transanal total mesorectal excision for rectal cancer: outcomes after 140 patients. J Am Coll Surg 2015;221:415-423.

23 Burke JP, Martin-Perez B, Khan A, Nassif G, deBeche-Adams T, Larach SW, Albert MR, Atallah S: Transanal total mesorectal excision for rectal cancer: early outcomes in 50 consecutive patients. Colorectal Dis 2016;18:570-577.

24 Arezzo A, Passera R, Salvai A, Arolfo S, Allaix ME, Schwarzer G, Morino M: Laparoscopy for rectal cancer is oncologically adequate: a systematic review and meta-analysis of the literature. Surg Endosc 2013;29:334-348.

25 Veltcamp Helbach M, Koedam TWA, Knol JJ, et al: Residual mesorectum on postoperative magnetic resonance imaging following transanal total mesorectal excision (TaTME) and laparoscopic total mesorectal excision (LapTME) in rectal cancer. Surg Endosc 2018;DOI: 10.1007/s00464-018-6279-9.

26 Mege D, Hain E, Lakkis Z, Maggiori L, Prost à la Denise J, Panis Y: Is trans-anal total mesorectal excision really safe and better than laparoscopic total mesorectal excision with a perineal approach first in patients with low rectal cancer? A learning curve with casematched study in 68 patients. Colorectal Dis 2018;20:O143-O151.
7 Chen C-C, Lai Y-L, Jiang J-K, et al: Transanal total mesorectal excision versus laparoscopic surgery for rectal cancer receiving neoadjuvant chemoradiation: a matched case-control study. Ann Surg Oncol 2016;23:1169-1176.

28 Atallah SB, DuBose AC, Burke JP, et al: Uptake of transanal total mesorectal excision in North America. Dis Colon Rectum 2017;60 1023-1031.

29 Marks JH, Montenegro GA, Salem JF, et al: Transanal TATA/TME: a case-matched study of taTME versus laparoscopic TME surgery for rectal cancer. Tech Coloproctol 2016;20: 467-473.

30 Rasulov AO, Mamedli ZZ, Gordeyev SS, et al: Short-term outcomes after transanal and laparoscopic total mesorectal excision for rectal cancer. Tech Coloproctol 2016;20:227-234.

31 Lelong B, Meillat H, Zemmour C, et al: Shortand mid-term outcomes after endoscopic transanal or laparoscopic transabdominal total mesorectal excision for low rectal cancer: a single institutional case-control study. J Am Coll Surg 2017;224:917-925.

32 Ortiz H, Biondo S, Codina A, et al: Hospital variation in anastomotic leakage after rectal cancer surgery in the Spanish Association of Surgeons project: the contribution of hospital volume. Cir Esp 2016;94:213-220.

33 Markar S, Gronnier C, Duhamel A, et al: Pattern of postoperative mortality after esophageal cancer resection according to center volume: results from a large European Multicenter Study. Ann Surg Oncol 2015;22: 2615-2623.

34 Hyman NH, Osler T, Cataldo P, et al: Anastomotic leaks after bowel resection: what does peer review teach us about the relationship to postoperative mortality? J Am Coll Surg 2009; 208:48-52.

35 Penna, M, Hompes R, Arnold S, et al: Incidence and risk factors for anastomotic failure in 1594 patients treated by transanal total mesorectal excision. Ann Surg 2018;DOI: 10.1097/SLA.0000000000002653. 